\title{
ENSURING INTEGRITY OF WELDED STRUCTURES AND CONSTRUCTIONS AT THEIR LONG-TERM SERVICE WITH APPLICATION OF RENOVATION TECHNOLOGIES
}

\author{
O.I. STEKLOV ${ }^{1}$, A.A. ANTONOV ${ }^{1}$ and S.P. SEVOSTIANOV ${ }^{2}$ \\ ${ }^{1}$ I.M. Gubkin Russian State University of Oil and Gas \\ 65 Leninsky Ave., 119991, Moscow, RF. E-mail: svarka@gubkin.ru \\ ${ }^{2}$ Company «Gazprom VNIIGAZ» \\ PO 130, 115583, Moscow, RF. E-mail: VNIIgaz@vniigaz.gazprom.ru
}

\begin{abstract}
Main pipelines in the Russian Federation have been in operation for a long time. Rate of failures in them because of initiation of various corrosion and stress-corrosion defects has increased. Application of welding repair technologies allows considerably lowering the risk of pipeline integrity violation. However, application of welding technologies in repair of pipelines in long-term service requires allowing for additional factors, which are not encountered in work performance on new pipelines. This and additional weldability studies, as well as certain requirements to welding consumables and allowing for stressed state resulting from application of renovation welding technologies, are described in this paper. 9 Ref., 8 Figures.
\end{abstract}

Keywords: main pipeline, repair technologies, weldability, corrosion, stress corrosion cracking, requirements to welding consumables, residual stresses, ultrasonic impact treatment

Most of welded structures and constructions, making up half of the country's metal reserves and built in the pre-restructuring period, are at the stage of ageing and failure rate increase because of damage accumulation, which is due to degradation processes in metals, fatigue, creep and corrosion.

Average age of oil-and-gas pipelines is more than 30 years and more than $70 \%$ of tank fleet have exhausted their specified service life. Bridges, overpasses and other facilities are in a complicated state. A considerable part of housing and communal facilities require renovation. Therefore, one of the important problems of

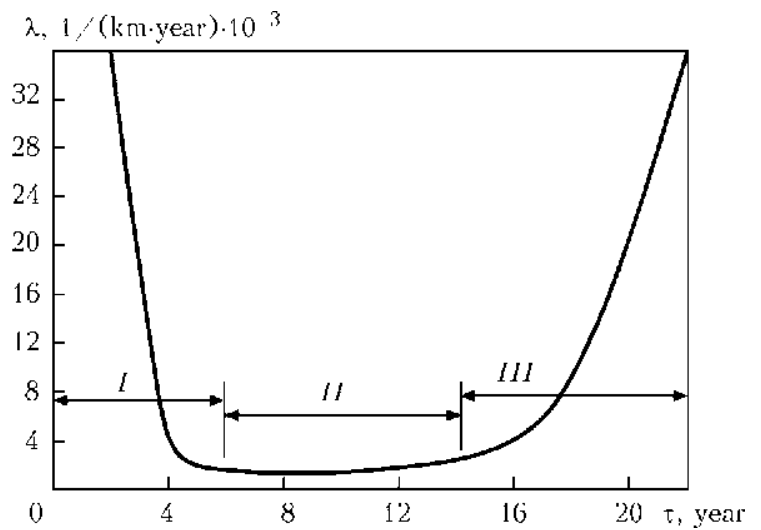

Figure 1. Dependence of specific failure rate index on service life of main oil pipelines (for $I-I I I$ see the text)

(c) O.I. STEKLOV, A.A. ANTONOV and S.P. SEVOSTIANOV, 2014 welding fabrication, alongside implementation of new projects, is maintaining the integrity of welded structures after long-term service using renovation welding and related technologies in order to prevent technogeneous and ecological catastrophies. Solution of this problem is considered in the case of main oil-and-gas pipelines.

A characteristic regularity of failure rate in the case of analysis of technical condition of the entire system of main oil pipelines, conducted in 1990s [1], is shown in Figure 1. Specific failure rate index $\lambda(1 / 1000 \mathrm{~km} \cdot \mathrm{year})$, depending on operation life $\tau$ of the main pipelines, is characterized by three periods:

$I$ - debugging, period of early failures at decreasing rate, when defficiencies of design, construction and welding-assembly operations are revealed;

$I I$ - normal operation with failures, predominantly of random nature;

III - increase of failure rate, in connection with degradation processes in the metal, protective coatings and corrosion.

Such a situation is characteristic also for main gas pipelines, as well as other facilities of oiland-gas complex [2]. In connection with the above-mentioned problems, an extremely urgent issue now is that of monitoring and assessment of the predicted life of constructions to determine the admissible terms of service, repair and renovation, prediction and assessment of technogeneous and economic risk. The basis of monitoring is technical diagnostics «by the state». 
Specialized monitoring systems are developed for various objects, allowing for the structure features and service conditions.

For gas-and-oil pipeline systems a complex three-level monitoring system is promising [3], which includes:

- geotechnical diagnostics based on aerospace monitoring data;

- in-pipe diagnostics;

- ground-based instrumental diagnostics, primarily, of potentially hazardous pipeline sections, detected by the data of in-pipe and geotechnical diagnostics.

Such a comprehensive approach to evaluation of gas pipeline technical state allowed improving the effectiveness of planning diagnostic and repair operations, as well as reliability of the entire gas transportation system and somewhat lowering accident rate [4].

Owing to improvement of methods of pipeline condition diagnostics and evaluation using inpipe flaw detection, a large number of defects of corrosion and corrosion-mechanical origin are detected on pipeline outer surface.

The most critical kind of defects are stress corrosion cracks, i.e. stress corrosion cracking (SCC) defects or their clusters (in the form of «crack field»), which have a predominantly longitudinal orientation and are located both in base metal and in the zone of shop longitudinal welds. This kind of defects are responsible for up to $70 \%$ of emergency failures of main gas pipelines.

Currently available normative documents specify the dimensions of admissible defects, determining their rejection level. SC cracks, the depth of which goes beyond negative tolerance for pipe wall thickness, were qualified as inadmissible defects, which must be removed (cutting-out pipe defective section). Calculation of safe pressure can be an alternative, at which the defective pipeline can fulfill its function without failure, but with productivity loss during product pumping. It should be noted that in such a situation the operators face several problems.

The first is to establish the actual technical state before assigning the overhauling status to the object, with complete or partial replacement of defective elements, sections, pipes, etc. At this stage either the project or most of the kinds of resources for repair operations performance are still absent. This stage is characterized by that the object still cannot be taken out of service for overhauling, but operative data about its technical state have already been obtained. This period, as a rule, is associated with completion of in-pipe examination of the pipeline and obtaining first preliminary (express), and then also final report on pipe defectiveness state.

Second problem in development of the above situation in the object in service consists in that when obtaining information about the defects preventing normal (without pressure lowering) pipeline operation, repair operations on defective section replacement cannot be performed because of impossibility of bringing heavy construction machinery to the site. In terms of location this is mainly true for pipelines in marsh, flood-plain and water barrier crossing areas. Timewise, it coincides with spring-summer period and autumn, up to marsh freezing and establishing of winter passageways along the route. Thus, starting from seasonal thawing of marshes through the entire summer period of operation up to autumn-winter freezing of marshes and creating ice crossings the operators are limited as to promptness of removing defects, preventing pipeline normal service.

The first problem can be partially solved by eliminating defects before pipeline taking out of service for overhauling, through involving service resources and performance of emergency-reconditioning repair. Now the second problem is associated with an unsurmountable obstacle conditions, under which such inadmissible defects as SC cracks cannot be eliminated by widely accepted technologies. The more so, since in the majority of normative documents such defects are unrepairable, and are eliminated by the only method of cutting-out the defective section and mounting, welding-in of a new pipe.

Special repair technologies play a particular role under these conditions for the operators. These technologies, without cutting-out the defective section and, hence, without involving a large complex of heavy construction machinery, allow performance of repair, restoring pipeline operability. Figure 2 gives the classification of these technologies. Such technologies include application of reinforcing elements (sleeves) ( $\mathrm{Fi}-$ gure 3) and repair welding (building-up) of all kinds of defects, including such hazardous defects as SCC [5].

Application of technology of defect repair by welding (building-up) after obtaining information about inadmissible hazardous defect, preventing normal operation, will allow operators ensuring its elimination by repair operations, also in difficult-of-access marshy areas. Another advantage provided by such technologies is the ability to restore the pipe without its replacement.

Application of repair welding (building-up) technologies for structures after long-term serv- 


\section{INTERNATIONAL CONFERENCE «WELDING CONSUMABLES》}

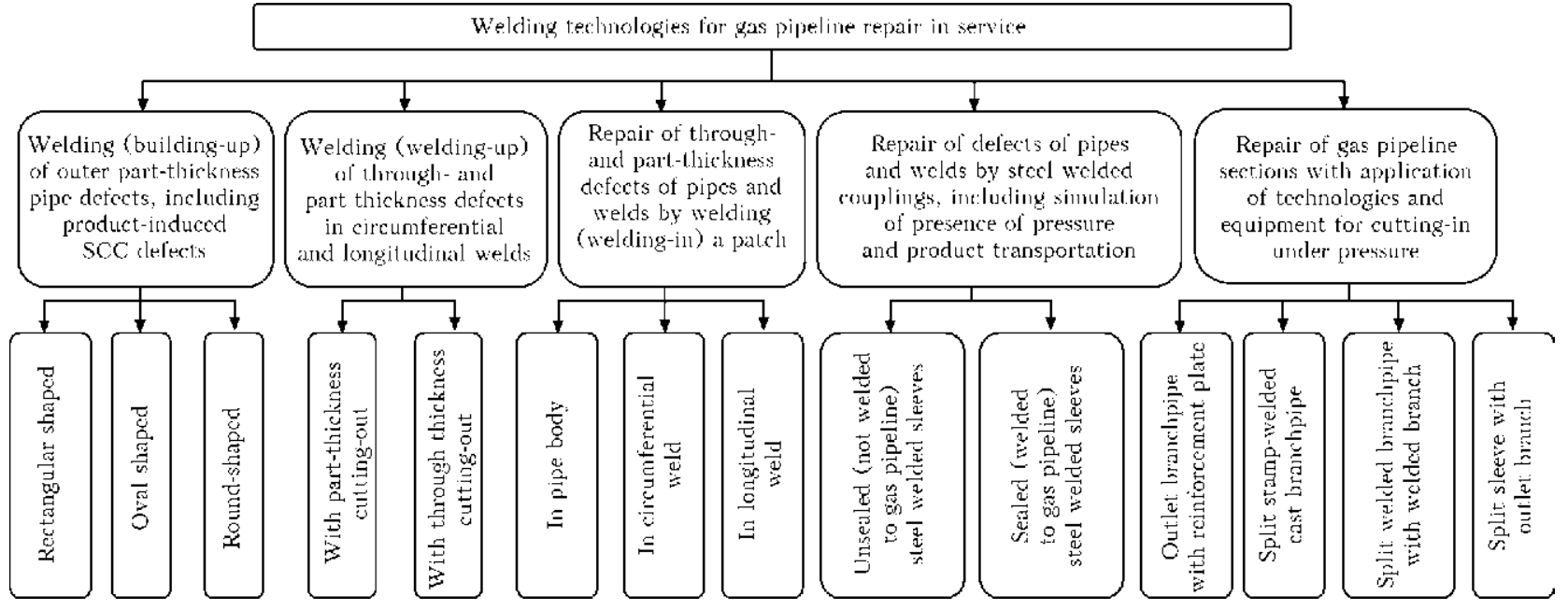

Figure 2. Welding technologies for gas pipeline in-service repair
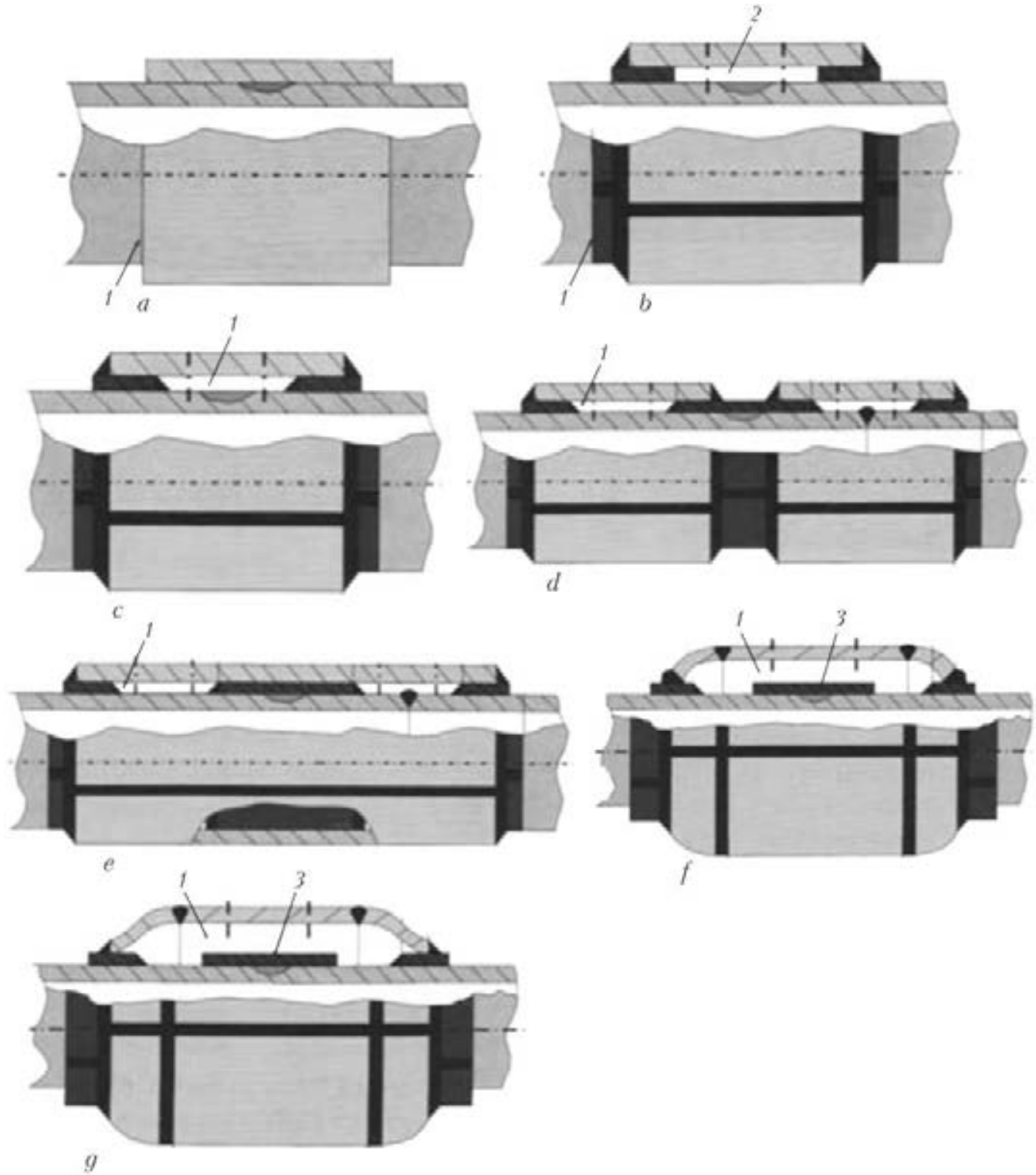

Figure 3. Schematics of repair by welded sleeves of defects in pipes and welds of sections of main gas pipeline linear part: $a, b$ - unsealed reinforcing sleeves; $c-g$ - sealed reinforcing sleeves and sleeve assemblies; 1 - sealant; $2-$ composite; 3 - temporary sleeve 
ice raises a number of key issues: evaluation of material weldability after long-term service; substantiated selection of welding (filler) consumables; optimization of technological process of welding (building-up); substantiation of application of additional postweld related technologies.

Summing up, the following can be noted.

In long-term service of equipment, an essential lowering of weldability of metal being repaired is possible, in connection with degradation processes in the metal as a result of strain ageing, saturation with active reagents from natural and technogeneous media, that requires analysis allowing for the conditions and term of service. Particularly important is evaluation of material weldability under service conditions at the impact of hydrogen-evolving and hydrogen-producing media and for structures operating at elevated temperatures under creep conditions. Unfortunately, no systemic studies on this problem have been performed so far.

Selection of filler materials, allowing for the impact of active media, should ensure the speci- fied strength characteristics of the deposited metal and its «cathodicity» relative to base metal.

Proceeding from design strength of the object and allowing for good weldability, it is rational to ensure strength characteristics from the condition of $\sigma_{\mathrm{t}}^{\mathrm{w}}, \sigma_{\mathrm{y}}^{\mathrm{w}} \leq \sigma_{\mathrm{t}}^{\mathrm{m}}, \sigma_{\mathrm{y}}^{\mathrm{m}}$ (where «w» and «m» indices are the welded joint and base metal, respectively).

To ensure resistance to electrochemical corrosion, the following condition should be fulfilled: $\varphi^{\mathrm{w}} \geq \varphi^{\mathrm{m}}$ (where $\varphi^{\mathrm{w}}, \varphi^{\mathrm{m}}$ are the electrode potentials of welded (built-up) and base metal, respectively).

Technology of repair-reconditioning operations is determined, allowing for the above principles, in particular without hydrocarbons bleeding [6].

We will single out only the first group welding (building-up) of outer part-through defects of pipes, including product-induced SCC defects, from the general classification of welding technologies in gas pipeline repair (see Figure 2). Criteria for application of this kind of repair are as follows:
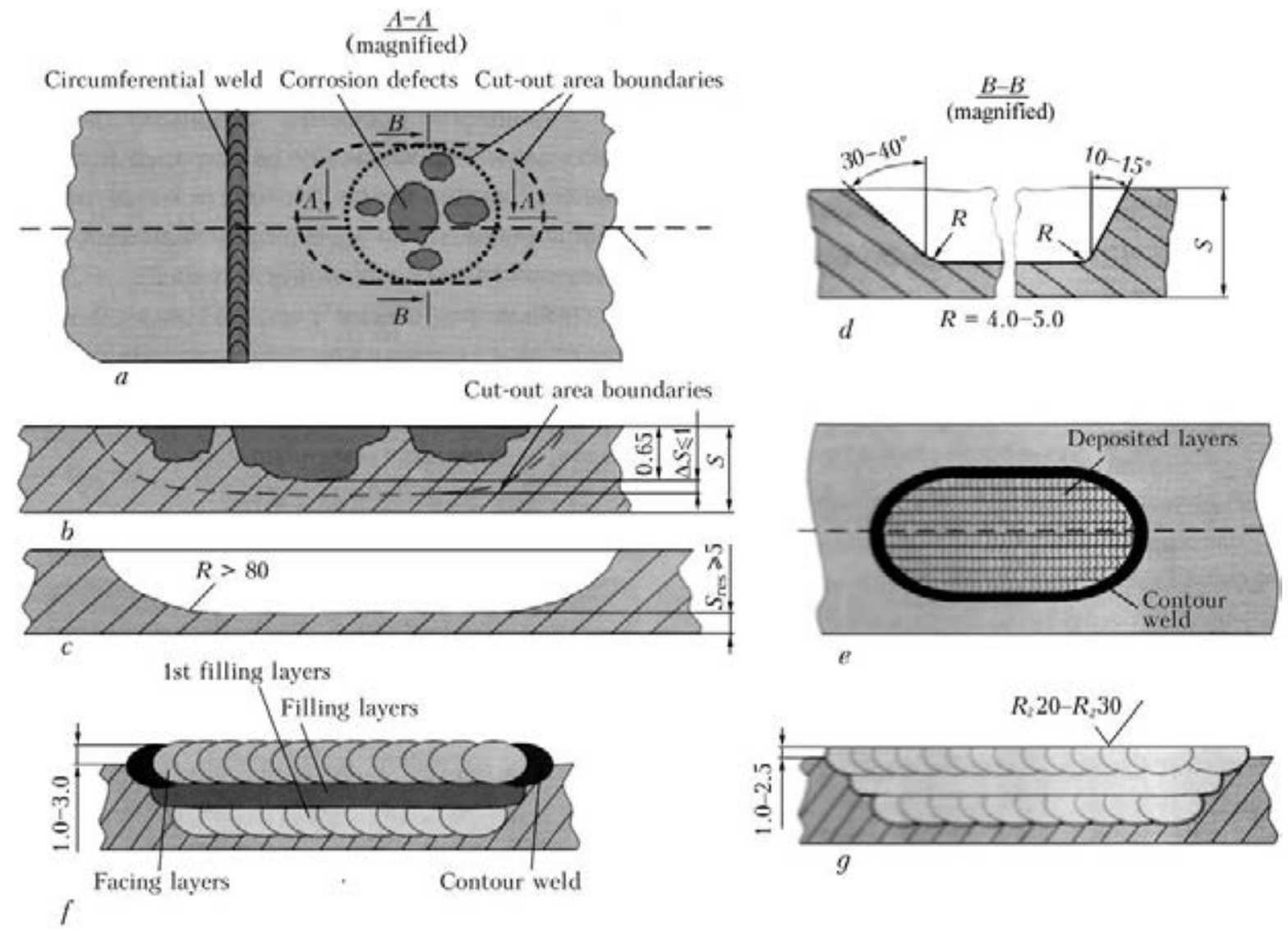

Figure 4. Sequence of technological operations of repair by welding (building-up) of part-thickness outer defects in pipe metal: $a$ - appearance of pipe with defective section; $b$ - transverse section of pipe along $A-A$ line with defective area, respectively; $c-$ transverse section of pipe along $A-A$ line after mechanical cutting-out of defective layer; $d-$ transverse section of pipe along $B-B$ line after mechanical cutting-out of defective layer; $e$ - pipe appearance after repair; $f-$ transverse section of pipe along $A-A$ line after repair; $g$ - transverse section of pipe along $B-B$ line after mechanical scraping of facing layer 


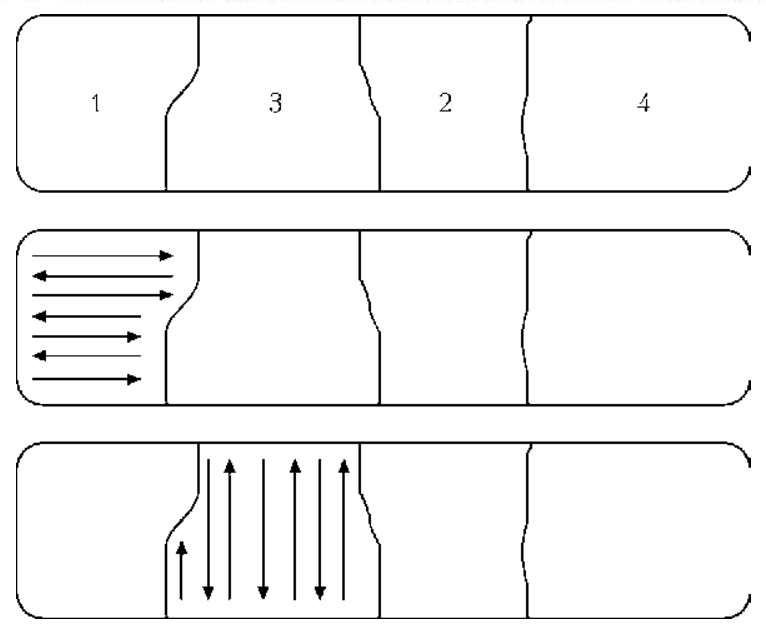

Figure 5. Dividing extended repair section into separate zones 1-4, and sequence of filling them with deposited metal using welding technologies

- ensuring temperature-plastic stability of molten and heated metal in the zone of heat source impact (arc, plasma), proceeding from the conditions of «not burning through» and preservation of strength in the localized heat zone;

- admissible deformability of pipe body in welding (building-up) zone under the impact of inherent stress-strain state in thermodeformational welding cycle, proceeding from the condition of strength of a pipeline with geometry defects;

- admissible level of inherent residual welding stresses in building-up zone.

For gas pipeline admissible value of residual welding stresses in building-up zone is determined from the condition of prevention of SCC, arising at total working $\sigma_{\text {work }}$ and residual $\sigma_{\text {res }}$ stresses exceeding threshold (critical) $\sigma_{\text {th }} \sigma_{\text {work }}+$ $+\sigma_{\text {res }} \leq \sigma_{\text {th }}$. Hence,

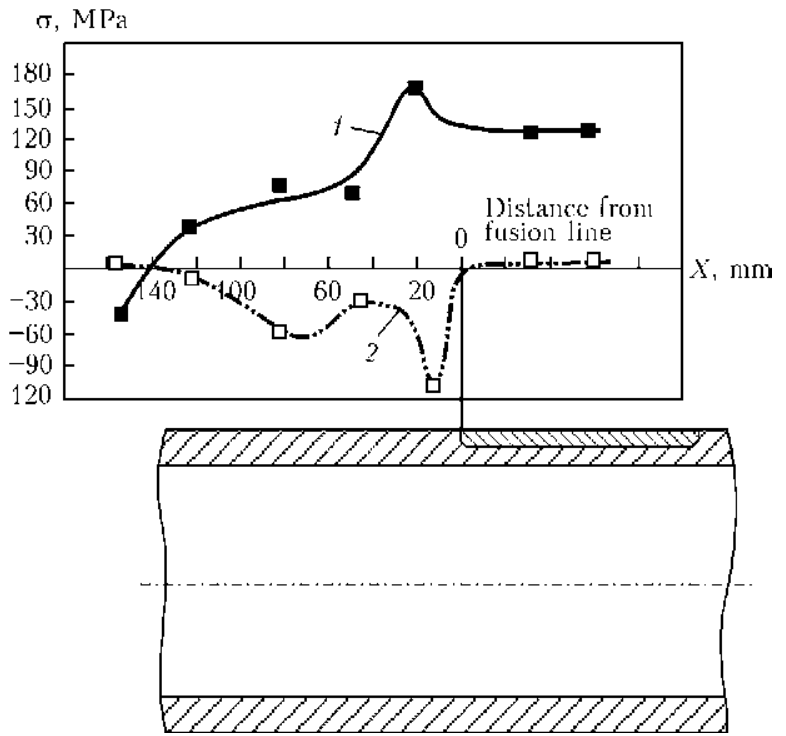

Figure 6. Characteristic diagram of residual stress distribution in the axial direction after repair building-up: 1 longitudinal; 2 - circumferential stress

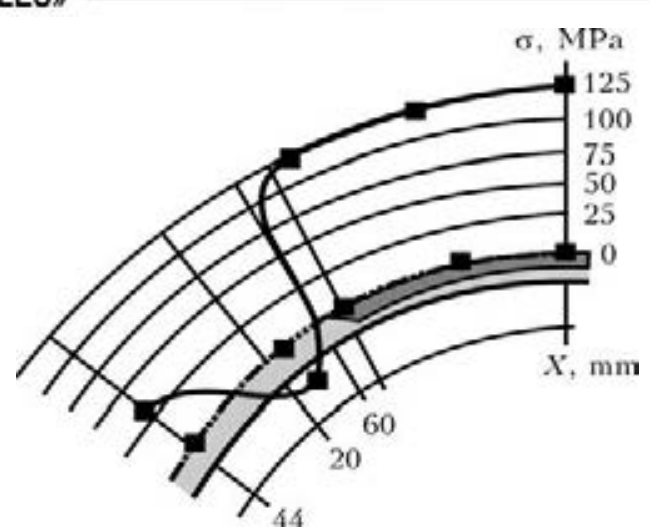

Figure 7. Characteristic diagram of residual stress distribution in the circumferential direction after repair by building-up: solid curves - longitudinal stresses; hatched circumferential

$$
\sigma_{\text {res }} \leq \sigma_{\text {th }}-\sigma_{\text {work }}
$$

Allowing for safety factor $\sigma_{\text {work }} \approx 0.5 \sigma_{\mathrm{y}}$, and $\sigma_{\text {th }}$ value is equal to approximately $0.76 \sigma_{\mathrm{y}}$ based on generalization of failure rate statistics [7]. Admissible value of $\sigma_{\text {res }} \leq(0.2-0.3) \sigma_{\mathrm{y}}$.

An important condition of this technology is welding with a controllable thermal cycle, with heat input and current, minimum admissible in terms of process stability:

$$
q / V \rightarrow \min , \quad I_{\mathrm{w}} \rightarrow \min .
$$

For example, in practice for manual arc welding with $2.6-3.2 \mathrm{~mm}$ consumable electrodes it corresponds to $I_{\mathrm{w}}=90-120$ A. Schematics of repair technologies are given in Figure 4.

In welding-up of extended defects, in order to reduce pipe body deformation, caused by thermodeformational cycle of welding, building-up zone should be divided into smaller sections with reverse-successive direction of welding (building-up) (Figure 5)

A procedure and portable equipment have been developed in order to determine the level and distribution of $\sigma_{\text {res }}$ in building-up zone. The procedure is based on application of nondestructive methods of express-diagnostics of stressstrain state (for instance, equipment based on Barkhausen noise method) at the first stage, allowing detection of the areas of examined section with maximum values of residual stresses. More

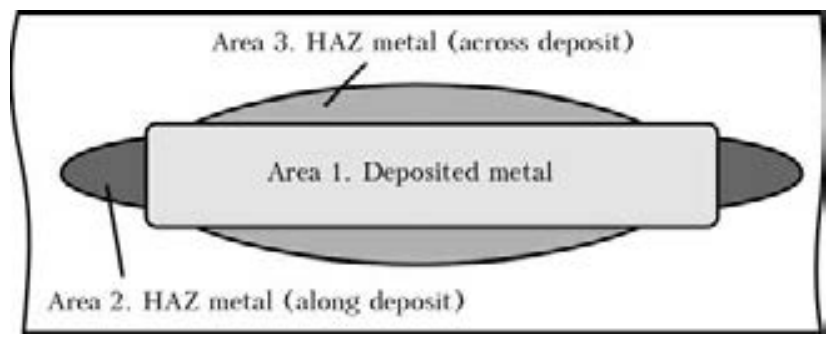

Figure 8. Characteristic field of residual stresses after pipe deposition 
precise determination of residual stress value in the detected areas is performed using the method of drilling a blind hole with recording of displacement by speckle-interferometer, in keeping with GOST R 52891-2007. Integrated application of several methods, fundamentally different by their operating principles, allows increasing final result validity. Investigations revealed that residual stress fields after repair building-up have a characteristic pattern of distribution in the axial and circumferential directions, independent on building-up technology [8] (Figures 6 and 7).

Thus, after any repair building-up, a field of residual stresses, shown in Figure 8, develops in the main pipe.

In order to fulfill the specified conditions, recommendations on the technology of postweld treatment of building-up zone have been developed. A fundamental point is localized lowering of residual welding stresses in the zone of their maximum values. Classical thermal methods of lowering the level of residual stresses are not always applicable, that is related both to complexity of organizing heating only in the local deposit area, and to ineffectiveness of such a method in terms of cost.

In recommendations on postweld treatment, a considerable place is taken up by technologies of local impact on individual zones in the deposit area, having peak values of tensile residual stresses. Lowering of such peak values involves general redistribution of residual stress field, because of their mutual balance. A promising approach is lowering peak values, ensuring total favourable redistribution of residual stresses, by the method of ultrasonic peening treatment [9].

\section{Conclusions}

1. Application of special welding technologies allows extension of active service life of main pipelines.

2. When preparing for application of welding technologies in main pipelines after long-term service, it is necessary to perform additional weldability studies.
3. When selecting welding consumables, attention should be given to ensuring the specified strength characteristics and cathodicity relative to base metal.

4. Admissible residual stresses after performance of repair building-up should not exceed 20$30 \%$ of yield point.

5. Residual stress fields, developing after repair building-up performance, have a common characteristic shape, irrespective of deposition sequence or direction of beads. The highest value of tensile stresses develops in the base metal near building-up zone along pipe axis.

6. Application of local methods of postweld impact on residual stress fields allows lowering stress-strain state level in the impact zone, in the built-up section and in base metal regions adjacent to building-up zone.

1. Chernyaev, V.D., Chernyaev, K.V., Berezin, V.L. et al. (1997) System reliability of main transport of hydrocarbons. Ed. by V.D. Chernyaev. Moscow: Nedra.

2. Varlamov, V.L., Kanajkin, V.A., Matvienko, A.F. et al. (2012) Monitoring of defects and prediction of state of Russian main gas pipelines. Ekaterinburg: UNPTs.

3. Steklov, O.I. (2006) Complex technical diagnostics of main gas-and-oil pipelines. Territoriya Neft $i \mathrm{Gaz}$, 4, 20-23; 5, 12-17; 6, 48-55.

4. Varlamov, D.P., Dedeshko, V.N., Kanajkin, V.A. et al. (2012) Improvement of reliability of main gas pipelines by using repeated in-pipe flaw detection. The Paton Welding J., 3, 20-25.

5. Vyshemirsky, E.M., Shipilov, A.V., Bespalov, B.I. et al. (2006) New welding and repair technologies in construction and repair of gas pipelines. Nauka $i$ Tekhnika v Gaz. Promyshlennosti, 2, 27-34.

6. Steklov, O.I., Shafikov, R.R., Sevostianov, S.P. (2009) Theoretical-experimental substantiation of possibility of main pipeline repair using welding technologies without interrupting of gas pumping. Svarochn. Proizvodstvo, 7, 12-17.

7. Steklov, O.I., Varlamov, V.P. (2012) Assessment of threshold stress level of corrosion cracking in system of main pipelines. Truboprovod. Transport (Teoriya $i$ Praktika), 3, 4-9

8. Antonov, A.A., Steklov, O.I., Antonov, A.A. (Jr) et al. (2010) Investigation of technological residual stresses in welded joints of main pipelines. Zagot. Proizvodstvo v Mashinostroenii, 3, 13-19.

9. Antonov, A.A., Letunovsky, A.P. (2012) Reduction of residual welded stresses by ultrasonic peening method. Truboprovod. Transport (Teoriya $i$ Praktika), 2, 21-26. 